\title{
PLANNING A PARTY: A COMMUNICATIVE ACTIVITY
}

\begin{abstract}
Alison Norman
This communicative activity for the ESL classroom draws on an idea presented in Pinch and Ouch: English Through Drama (Nomura, 1982). It is an activity which has been used with equal success in advanced, intermediate, and upper beginners level classes as well as in multi-level classes. It works best in a class of 15-20 students. It can be used in a culturally homogeneous class, but it is certainly more interesting in a multi-cultural class; the more cultures represented the better.

The activity involves the students performing three language functions: inviting, accepting an invitation and declining an invitation, in a realistic context. The grammatical structures used in performing the functions can easily be varied by the teacher according to the students' abilities. The activity can also lead into a discussion of cultural differences regarding social rules and values. In the follow-up discussion, the students may practice the language functions of expressing intentions, stating expectations and making comparisons.

The features of this activity are that it provides for a great deal of student interaction, allows the students to be creative and produces unexpected situations from which both the students and teacher can learn.

The activity can be best described by dividing it into four tasks.
\end{abstract}

\section{TASK 1}

The students practice the functions of inviting, accepting an invitation, and declining an invitation. This can be done using a language master or taped dialogues. The dialogues can be simple for beginners:

A: I'm having a tea party on Saturday afternoon. Can you come?

B: Yes, I can. What time is it at?

A: 3 p.m.

B: Fine. See you then.

or considerably more complicated for advanced students:

A: I was thinking of having a get-together on Friday evening. Do you think you could make it?

B: Oh dear! I don't think so. I've already made other arrangements for Friday evening.

A: What a pity! Well, never mind. Perhaps next time.

B: Right. Thanks anyway for inviting me.

In a multi-level class, each level can practice a slightly different dialogue, but all dialogues must be comprehensible to all levels so that the whole class can interact in the next step. 


\section{TASK 2}

The students fill out a 4 or 5 day agenda for themselves and plan a party during a time slot in which they have no prior commitments. In order for the students to complete this task, the teacher should take the students through the following steps:

1. The teacher elicits from the students a list of the different possible kinds of parties they could plan to have. This can be done through large group brainstorming or small group discussion. It provides an opportunity for students from different ethnic backgrounds to share information about their social gatherings, and the teacher can provide information about Canadian occasions for parties with which they may not be familiar (e.g., cocktail parties, baby showers).

2. The teacher distributes a simple engagement calendar for 4 to 5 days to the students (see Figure 1). It is best if the first day of the calendar is the day on which the class is taking place. Each day is divided into 3 time units-morning, afternoon, evening. It is usually necessary to have Saturday or Sunday on the calendar, preferably both.

\begin{tabular}{|l|l|l|l|l|l|}
\hline & Wed. & Thurs. & Fri. & Sat. & Sun. \\
\hline Morning & & & & & \\
\hline Afternoon & & & & & \\
\hline Evening & & & & & \\
\hline
\end{tabular}

Figure 1. An engagement calendar.

The students first fill in all the genuine commitments they have for the next 5 days. It is important for the students to understand that they only fill in things that they must do-e.g., doctor's appointments, babysitting jobs, work, English classes-and not such things as washing clothes or shopping which could easily be delayed or performed at another time.

3. When the students have filled in their commitments on the calendar, they should then plan a party for one of the time slots in which they are free. They must decide what kind of party they wish to have, at what time it will start, etc. If the teacher wishes, students can be reminded to block in adequate time for preparation for their party on their calendars. 


\section{TASK 3}

The students invite as many of their classmates to their party as possible. The goal is to get the maximum number of guests to attend. As they are moving around the room inviting, they will, of course, also be accepting or declining the invitations of others. It is important that they write down on their calendar any invitations for parties at the same time. They should also keep track of who is coming to their party.

\section{TASK 4}

Each student reports to the teacher, who records, on the blackboard, the kind of party they are holding, the time it is to be held and the number of guests who are going to attend. The teacher can help the students organize their schedules appropriately. As a follow-up to the activity, the teacher can spotlight one or two parties and ask the "guest" such questions as:

1. What are you going to wear to the party?

2. What are you going to take, if anything?

3 . What time are you going to arrive?

4. How long do you expect to stay?

5. What do you expect to eat and drink?

6. What do you expect to do?

These questions often reveal surprising cultural differences and provide the teacher an opportunity to impart useful information to the students about Canadian etiquette.

\section{REFERENCE}

Nomura, Yoko. (1982). Pinch and ouch: English through drama. Tuscon, Arizona: Lingual House.

\section{THE AUTHOR}

In 1969 Alison Norman began teaching EFL in Thailand where she spent four years working at both a teachers' college and a university. Ms. Norman has been teaching ESL at the Vancouver Community College since 1980. She is involved in the School Canadiana Project where she teaches ESL to beginner level Chinese immigrants and with the Neighbourhood English Department where she teaches ESL to multi-level, multi-lingual ethnic groups. 